\title{
Thigh compartment syndrome secondary to intertrochanteric hip fracture in a quadriplegic patient: case report
}

\author{
R L Rimoldi MD, D A Capen MD \\ Spinal Cord Injury Service, Rancho Los Amigos Medical Center, 7601 East Imperial \\ Highway, Downey, California 90242, USA.
}

Compartment syndromes in the thigh are rare and the diagnosis may be difficult in the light of subtle early physical findings in the patient with spinal cord injury. Clinical awareness of the impending compartment syndrome is important to provide timely proper treatment and avoid disabling deformities. A compartment syndrome should not be ignored in the paraplegic, because the potential for late fibrosis and contractures may limit the independence of such patients. Greater awareness and index of suspicion are needed to successfully recognize and promptly treat the compartment syndrome in this patient population.

Key words: thigh compartment syndrome; thigh; quadriplegia; fasciotomies.

\section{Introduction}

Compartment syndrome in the thigh is an uncommon condition that is infrequently reported in the literature. ${ }^{1-10}$ Previous reports associate the syndrome with femoral fractures, ${ }^{1,3,5,9}$ application of anti-shock trousers, ${ }^{2}$ compression after drug overdose, ${ }^{6,7}$ muscle overuse ${ }^{8}$ and contusion. ${ }^{1,7.10}$ Compartment syndrome of the thigh in the patient with spinal cord injury is very rare. To our knowledge there are no previously reported cases in this patient population. Here the authors report a compartment syndrome of the proximal thigh in a patient with spinal cord injury and impaired sensation.

\section{Case report}

A 33 year old man with functional C6 quadriplegia from a previous motor vehicle accident presented 3 days after a fall. He felt a 'pop' in his right hip. This patient is a wheelchair ambulator and was performing a standing pivot transfer at the time of the fall. He landed on his buttock area and complained of an ache extending up to his right flank and massive swelling in his right thigh. The patient was not able to differentiate between sharp or dull sensation in the lower extremities because of the previous injury to his cervical spine. Further examination revealed crepitus with gentle range of motion to the right hip. There was no appreciable pain on passive stretch of the muscles of the anterior, medial and posterior compartments of the thigh. Thigh girth was measured $20 \mathrm{~cm}$ proximal to the cephalad pole of the patella. There was a difference of $8 \mathrm{~cm}$ between the right and left thighs. The right thigh was tense to palpation. Radiographs revealed a two-part intertrochanteric fracture of the right proximal femur. Compartment syndrome was suspected. Anterior compartment pressure of the right thigh measured in the emergency room using the triple manometer technique ${ }^{4}$ was $120 \mathrm{~mm}$ of mercury. His blood pressure at this time was $140 / 95 \mathrm{~mm} \mathrm{Hg}$. The patient was taken immediately to the operating room where the right thigh was decompressed through a lateral skin incision. Intraoperative findings demonstrated a fracture hematoma extending into the anterior compartment. The vastus lateralis and rectus femoris muscles were dusky in appearance but there was no evidence of myonecrosis. Fasciotomies were performed. Repeat compartment pressures were normal. The incision was packed open. A delayed primary closure of the wound was performed one week after the initial fascio- 
tomy. The patient's fracture was successfully treated in traction and the remaining hospital course was uneventful.

\section{Discussion}

The devastating effects of an unrecognized compartment syndrome are well documented. ${ }^{11,12}$ Compartment syndrome resulting from acute trauma, muscle overuse, arterial ischemia, burns, compression dressings and infusion of intravenous fluids have been described. ${ }^{1-15}$ However, compartment syndrome in the thigh is extremely rare and has not been reported in the spinal cord injured patient.

The thigh has 3 compartments: anterior, medial and posterior, which are separated by fascial septa. The lateral intermuscular septum is quite substantial; however, the posterior and medial intermuscular septa are much thinner. ${ }^{9}$ The thigh, with its larger volume, can accommodate a greater degree of swelling before a compartment syndrome occurs. The diagnosis of compartment syndrome in the patient with impaired sensation requires greater insight than in the patient with normal neurological function. The cardinal signs, impaired sensation and pain on passive stretch of the muscle, are not helpful in diagnosing compartment syndrome in the spinal cord injured patient.
The diagnosis is only suggested by a history of trauma, swelling and firmness of palpation of the involved extremities. Thigh swelling and firmness in the quadriplegic patient is usually attributed to deep venous thrombosis or heterotopic ossification. However, compartment syndrome should be considered. When fracture, deep venous thrombosis and heterotopic ossification are not the cause of extremity swelling, the authors recommend compartment pressure monitoring.

The treatment of the compartment syndrome in the spinal cord injured patient can be debated. A patient who is limited to wheelchair mobilization does not require the use of lower extremity muscles. Therefore, myonecrosis and secondary fibrosis resulting from an untreated compartment syndrome may not initially affect the functional mobilization in the patient with neurological injury. However, the long term consequences must be considered. Myonecrosis and fibrosis may lead to late contractures. This impairs range of motion of the lower extremity joints, making it difficult for the patient to perform daily tasks such as transfers and lower extremity dressing skills. Therefore, the authors recommend that the compartment syndrome in the spinal cord injured patient should be treated aggressively with surgical decompression of the involved extremity.

\section{References}

1 Allen MJ, Stirling AJ, Crawshaw CV, Barnes MR (1985) Intercompartmental pressure monitoring of leg injuries: an aid to management. J Bone Joint Surg 67B: 53-57.

2 Bass RR, Allison EJ Jr, Reines HD, Yeagor JC, Pryor WH Jr (1983) Thigh compartment syndrome without lower extremity trauma following application of pneumatic anti-shock trousers. Ann Emerg Med 12: $382-384$

3 Clancy GJ (1985) Acute posterior compartment syndrome in the thigh. J Bone Joint Surg 67A: 1278-1280.

4 Matsen FA III, Winquist RA, Krugmire RB Jr (1980) Diagnosis and management of compartmental syndromes. J Bone Joint Surg 62A: 286-291.

5 Moore MR, Garfin SR, Hargens AR (1987) Case report. Compartment syndrome of the thigh complicating surgical treatment of ipsilateral femur and ankle fractures. J Orthop Trauma 1: 71-73.

6 Mubarak SJ, Owen CA (1975) Compartmental syndrome and its relation to the crush syndrome: a spectrum of disease. A review of eleven cases of prolonged limb compression. Clin Orthop 113: 81-89.

7 Mubarak SJ, Owen CA, Hargens AR, Garetto LP, Akeson WH (1978) Acute compartment syndromes: diagnosis and treatment with the aid of the wick catheter. J Bone Joint Surg 60A: 1091-1095.

8 Raether PM, Lutter LD (1982) Recurrent compartment syndrome in the posterior thigh. Report of a case. Am J Sportsmed 10: 40.

9 Tarlow SD, Achterman CA, Hayhurst J, Ovadia DN (1986) Acute compartment syndrome in the thigh complicating fracture of the femur. A report of three cases. J Bone Joint Surg 68A: 1439.

10 Viegas SF, Rimoldi RL, Scarborough M, Ballantyne GM (1988) Acute compartment syndrome in the thigh. A case report and review of the literature. Clin Orthop 234: 232. 
11 Mubarak SJ, Hargens AR (1981) Compartment syndrome in Volkmann's Contracture. WB Saunders, Philadelphia.

12 Whitesides TE Jr, Harada H, Morimoto K (1977) Compartment syndromes and the role of fasciotomy, its parameters and techniques. In: AAOS Instructional Course Lectures, Vol. 26. CV Mosby, St. Louis: 179-196.

13 Handler EG (1990) Superficial compartment syndrome of the foot after infiltration of intravenous fluid. Arch Phys Med Rehabil 71: 58.

14 Langen RP, Ruggieri R (1989) Acute compartment syndrome in the thigh complicated by a pseudoaneurysm. J Bone Joint Surg 71A: 762.

15 Parziale JR, Marino AR, Herndon JH (1988) Diagnostic peripheral nerve block resulting in compartment syndrome. Case report. Am J Phys Med Rehabil 67: 82. 